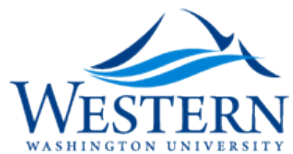

Western Washington University

Western CEDAR

$3-1985$

\title{
Comprehension, Irritation and Error Hierarchies
}

Shaw N. Gynan

Western Washington University, shaw.gynan@wwu.edu

Follow this and additional works at: https://cedar.wwu.edu/mcl_facpubs

Part of the Bilingual, Multilingual, and Multicultural Education Commons, and the Linguistics Commons

\section{Recommended Citation}

Gynan, Shaw N., "Comprehension, Irritation and Error Hierarchies" (1985). Modern \& Classical Languages. 58. https://cedar.wwu.edu/mcl_facpubs/58

This Article is brought to you for free and open access by the Humanities at Western CEDAR. It has been accepted for inclusion in Modern \& Classical Languages by an authorized administrator of Western CEDAR. For more information, please contact westerncedar@wwu.edu. 


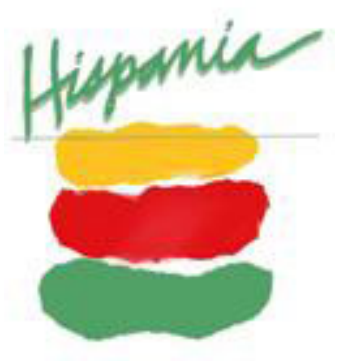

Comprehension, Irritation and Error Hierarchies

Author(s): Shaw Nicholas Gynan

Source: Hispania, Vol. 68, No. 1 (Mar., 1985), pp. 160-165

Published by: American Association of Teachers of Spanish and Portuguese

Stable URL: http://www.jstor.org/stable/341633

Accessed: 08-09-2015 17:36 UTC

Your use of the JSTOR archive indicates your acceptance of the Terms \& Conditions of Use, available at http://www.jstor.org/page/ info/about/policies/terms.jsp

JSTOR is a not-for-profit service that helps scholars, researchers, and students discover, use, and build upon a wide range of content in a trusted digital archive. We use information technology and tools to increase productivity and facilitate new forms of scholarship. For more information about JSTOR, please contact support@jstor.org.

American Association of Teachers of Spanish and Portuguese is collaborating with JSTOR to digitize, preserve and extend access to Hispania. 


\title{
Comprehension, Irritation and Error Hierarchies
}

\author{
- Shaw Nicholas Gynan, The University of New Mexico
}

\section{Introduction}

There are several recurrent themes in the study of native speaker attitudes toward interlanguage. First among them treated in a recent review by Ludwig is comprehensibility, that is, the ease with which the native speaker can comprehend nonnative speech. ${ }^{1}$ Research in the area of native speaker attitudes toward nonnative speech reviewed in Ludwig has shown that formal errors are not well related to comprehensibility of interlanguage. "Irritation" is also a topic of considerable interest. An assumption underlying the study of irritation is that even if nonnative speech is comprehensible, the form of the message may be associated with a negative affective response from the native speaker. Certain formal or mechanical errors may be considered more important than others by native speakers. The ranking of errors by comprehensibility, irritation or other criteria is referred to as an error hierarchy. An interesting, detailed example of an error hierarchy based on both comprehensibility and irritation may be found in an article by Chastain. ${ }^{2}$

The data to be discussed is part of a larger study which compared attitudes of U.S. bilinguals and Spanish-speaking learners of English toward native and nonnative speech samples. ${ }^{3}$ Factor analysis of the data from this study demonstrates that the concept of irritation needs clarification. Native speaker response to interlanguage is not solely the result of irritation but rather of evaluation as well. In the present paper, the response of a native speaker toward language is shown to be largely evaluative and only slightly affective. Such a response is referred to here as a language attitude. Data will be presented below which demonstrate that error hierarchies based on language attitudes are tentatively valid with reference to very low language ability. Comprehensibility is related to phonological characteristics of primitive interlanguage more than to the morphosyntactic ones, but not sufficiently so to warrant a hierarchy in which phonology is ranked first because of its impact on comprehensibility. The findings show that problems with morphology and syntax (referred to simply as morphosyntax throughout this paper) are more salient to native speakers than those with phonology, despite the fact that comprehensibility is apparently somewhat related to phonological accuracy. The practical implications of these findings are that the internalization of morphosyntactic rules should produce a certain level of accuracy in order not to be salient to native speakers and that teachers should encourage accuracy in pronunciation not simply by drilling points of crucial contrast, ${ }^{4}$ but also by encouraging the student to view pronunciation in a global way and thereby to develop a general 'feel' for what sounds socially appropriate.

Many language teachers, and perhaps even most, use textbooks, teaching techniques and testing methods which emphasize the formal accuracy of student speech. Errors in form generally are not considered acceptable by the teacher. Studies which compare teacher attitudes and native speaker attitudes show that some teachers are considerably more severe in their ratings of nonnative speech on formal aspects. ${ }^{5}$ If these ratings are representative of teacher attitudes, then 'irritation' and proof of the existence of native speaker irritation is an issue of considerable importance. Studies of irritation generally involve an attempt to develop an error hierarchy which ranks errors in terms of the degree to which native speakers are annoyed by them. If native speakers are annoyed by certain errors, then perhaps the teacher should strive to eliminate those errors in the classroom. If, on the other hand, natives are not annoyed by any particular error, then another approach may be more appropriate.

Oller has theorized the existence of a global language factor which appears to explain common variance in different tests of language ability. ${ }^{6}$ Recently, this global language factor has been challenged on the grounds that a general or ' $g$ ' factor can be extracted by analysis of any data set. ${ }^{7}$ Although the general factor demonstrated by Oller may be an artefact of the type of factor analysis used, Oller still 
feels justified in claiming that there is a general language ability. ${ }^{8}$ There are notable exceptional cases of students who speak a foreign language fluently but with little grammatical accuracy or vice versa. Notwithstanding these interesting cases, improvements in student pronunciation, syntax and vocabulary seem to be related. As one area of performance improves, so do the others. ${ }^{9}$ If a learner is not outstandingly inaccurate in a particular aspect of his production, then it is possible that there is indeed no error hierarchy, and that speakers will respond to the various aspects of nonnative speech in a global manner.

Irritation, as treated by Chastain, Albrechtsen and others, appears to be similar to what has been defined in this paper as a language attitude. A precise definition of irritation and of language attitude presupposes a definition of attitude. According to some social psychologists, an attitude is a learned predisposition to respond in a consistently favorable or unfavorable way with regard to an object, entity, person or state. ${ }^{10}$ The way in which a person responds to an object needs to be specified in order to define more clearly what an attitude is. Attitude toward language may be measured by determining whether the listener feels good or bad about the language or whether the listener thinks the language is good or bad. The former attitude is affective, and the latter is evaluative. Irritation, by this definition, is an affective language attitude. Attitudes toward learners' language (not "irritation"), are evaluative and affective. People don't simply feel bad when they hear language they don't like, but rather they evaluate the language as being bad or good and may associate that attribute of the language with affect.

The following discussion will present evidence to support a number of working hypotheses. First, evaluative and affective language attitudes are not empirically distinguishable. Second, error hierarchies which assign greater gravity to morphosyntactic errors may be validated empirically. Finally, fine divisions in error hierarchies may not be validated empirically. These hypotheses, if true, indicate that "irritation" as such does not exist, that error hierarchies are too specific, and that after a certain level of language proficiency, attention to and direct correction of one problem area, pronunciation, is not warranted. Evidence presented here suggests applications and further confirms the validity of "monitor theory" and the related communicative or natural approach. ${ }^{11}$ The defense of communicative methods of language teaching presented here is novel and indirect, since social psychological evidence (as opposed to psycholinguistic evidence) is the basis of this research.

\section{Sample Population and Materials}

Nonnative speakers were recruited from fourth semester Spanish classes at the University of Texas at Austin and were asked to record a narrative description of transportation development by means of an oral composition technique, which utilizes a series of photographs to guide the narration and control the vocabulary used. Thereby external constraints on linguistic creativity are reduced, which is needed for elicitation of useful and realistic samples of interlanguage. ${ }^{12}$ This type of elicitation controls speech samples by requiring use of past, present and future tenses and by limiting each to a topic of neutral affective impact. Control of affective content has been commonly advocated and used in sociolinguistic research. ${ }^{13}$

Of the samples selected for use in the study, one was representative of fairly low ability and interest at the fourth semester level, and another was representative of above average ability and interest at the same level. Choice of these tapes, and of the native or native-like samples which were used in the larger study, were made on the basis of a particular linguistic feature which was hypothesized to be of value in predicting language attitudes: rate of speech as measured in words or segments per minute. The rate of speech of the low ability speaker (henceforth referred to as the 'beginner' for the sake of convenience) was 25 words per minute and that of the intermediate' speaker was 39 words per minute. Native speakers who participated in the elicitation experiments spoke at an average rate of 110 words per minute.

The tape samples were rated by 186 Spanish speakers from El Paso, Mexico and Venezuela. Most of these Spanish speakers were between the ages of 18 and 24 . They were recruited voluntarily, and were given ample time to read through the questionnaire and ask questions about its format and vocabulary. All participants were told that the purpose of the experiment was to measure their reactions to native and nonnative Spanish. 
The questionnaire consisted of statements about the vocabulary, syntax and pronunciation of the nonnative speaker. Another series of items dealt with social and affective assessment of the speaker as inferred from the speech, but these are not discussed here, as they are not language attitudes. All items on the questionnaire required the rater to agree or disagree with a positive statement by indicating the degree to which they agreed or disagreed on a seven-point scale. The use of a scale with an odd number of choices, allowed the participant the option of expressing no opinion. This was stressed to the native speakers who rated the tape samples. Most of the language-related questions measured evaluative language attitudes, while one measured affective language attitude.

Questions dealing with phonology asked how well the speaker pronounces $\mathrm{X}$, where $\mathrm{X}$ was a letter or series of letters. The words 'vowel,' 'consonant,' and 'Spanish' were also used in place of X. The inclusion of the item "b, d,g" was intended to measure the native speaker's reaction to occlusive pronunciation of intervocalic fricatives. The inclusion of the item " $\mathrm{p}, \mathrm{t}, \mathrm{k}$ " was intended to measure the native speaker reaction to aspiration of voiceless stops. By measuring the reaction to vowels, it was hoped to discover what the reaction was to diphthongization of simple vocalic nuclei. These and other sound problems are characteristic of Anglo pronunciation of Spanish. In pilot interviews with native speakers and tape samples in an informal setting which were carried out prior to the formal experiment, comments were made about the pronunciation of certain sounds, especially those noted above, and as well about the pronunciation of vibrants as retroflex vocoids. Another group of questions dealt with aspects of syntax and morphology, such as noun-adjective agreement, verb agreement, and sentence construction. Finally two items dealt with the listener's comprehension and like or dislike of the speech sample.

\section{Data Analysis and Results}

A standard factor analytic program was employed to determine whether or not one factor could be posited to explain native speakers' ratings. Responses to the items were intercorrelated, the resulting correlation matrix was converted so that tests with more shared variance would determine the factor struc- ture, principal factors were extracted and varimax rotation was performed to yield an interpretable solution. ${ }^{14}$ The terminal factor solution was based on responses by all native speakers who participated in the study to the tape samples. It was felt that the factor structure would vary from sample to sample, although there were no specific predictions regarding such differences. Therefore, factor solutions were derived for each individual sample.

In simpler terms, the factor analytic procedure enabled determination of whether raters tended to answer certain questions in the same way. The analysis demonstrated that indeed this was the case. Composite variables were constructed based on the factor analysis, and mean native speaker language ratings on each variable were calculated. These mean subjective ratings were then compared informally with objective linguistic measures of phonology and morphosyntax. This was done in an attempt to demonstrate which objective linguistic measures best predicted the subjective language measures.

Morphological errors were classified according to type of form/function unit involved, and a total morphosyntactic accuracy rate was calculated by dividing the number of correctly produced morphemes by the total number of morphemes in the sample. A series of phonological measures was made, including consonantal and vocalic accuracy, variation and number of segments per phonic group, and several types of hesitation, as originally identified by Maclay and Osgood. ${ }^{15}$ In Table 1 partial results of the analysis of the speech of the two nonnative speakers are presented.

The intermediate Anglo is slightly better than the beginner on most measures. The average clause length (ACL) is slightly longer, the intermediate language learner tends to subordinate a little more (SCI) and coordinate somewhat less than the beginner (MCI) and the average length of the sentences (ASL) in the speech of the intermediate language learner is longer. The intermediate learner uses correct morphemes $86 \%$ of the time, as compared to the beginner's rate of $82 \%$.

The intermediate learner pronounces consonants and vowels correctly $82 \%$ and $80 \%$, respectively, whereas the beginner pronounces consonants and vowels correctly only $79 \%$ and $70 \%$, respectively. Although the beginner tends to vary length of phonic groups 
more than the intermediate learner, the latter has longer breath groups, indicating that his speech is slightly less 'choppy' than that of

\begin{tabular}{|c|c|c|}
\hline \multicolumn{3}{|c|}{ Table 1: 'Linguistic Analysis of Speech Samples' } \\
\hline & Intermediate & Beginner \\
\hline Sample Time & $1: 41$ & $1: 38$ \\
\hline $\mathrm{ACL}$ & 8.2 & 6.8 \\
\hline $\mathrm{SCI}$ & 1.1 & 1.0 \\
\hline $\mathrm{MCI}$ & 1.4 & 1.5 \\
\hline ASL & 13.2 & 10.2 \\
\hline Total Words & 66 & 41 \\
\hline Morphological Accuracy & $86 \%$ & $82 \%$ \\
\hline Rate (words/minute) & 39 & 25 \\
\hline Consonant Accuracy & $82 \%$ & $79 \%$ \\
\hline Vowel Accuracy & $80 \%$ & $70 \%$ \\
\hline \multicolumn{3}{|c|}{ Number of segments per phonic group } \\
\hline Mean & 6.8 & 6.6 \\
\hline S.D. & 3.83 & 4.23 \\
\hline \multicolumn{2}{|l|}{ Total hesitations/minute } & 26.9 \\
\hline \multicolumn{3}{|c|}{ Non-phonemic lengthenings of segments/minute } \\
\hline & 7.1 & .6 \\
\hline \multicolumn{3}{|l|}{ Unfilled pauses/minute } \\
\hline \multicolumn{3}{|l|}{ Filled pauses/minute } \\
\hline & 8.3 & 8.6 \\
\hline \multicolumn{3}{|c|}{ Retraced hesitations/minute } \\
\hline & 6.4 & 4.9 \\
\hline
\end{tabular}

the beginner. A further indication of greater fluency on the part of the intermediate learner is a lower use of filled pauses (pauses during which one says 'um,' 'uh' and so on) and unfilled pauses (silent pauses) than the beginner's; however, the intermediate uses nonphonemic lengthening of segments and retraces more than the beginner, thus producing overall a greater rate of hesitation.

Partial results of factor analysis of the responses to speech of the intermediate student of Spanish are presented in Table 2. All of the items evaluative of the speech of the intermediate student loaded to one factor. It will be recalled that a seven-point scale was used for evaluation. The intermediate student received the lowest scores on morphosyntax. Items dealing with fluency, verb conjugation, sentence structure, and adjective agreement were assigned ratings around 2.1 or lower. On the other hand, the intermediate language learner was rated somewhat higher on items dealing with comprehensibility and pronunciation, receiving about 3.0. Appeal of accent, a more affective measure of language attitude, was apparently unrelated to the language factor.

It is quite difficult to compare the subjective ratings made by the native speakers in this
Table 2: 'Factor Analysis - Intermediate Anglo'

Factor 1-Language

\begin{tabular}{|c|c|c|c|}
\hline Item Label & Loadings & Means & Sigmas \\
\hline Diphthongs & .77 & 2.6 & 1.36 \\
\hline Vowels & .74 & 2.7 & 1.42 \\
\hline Pronunciation ptk & .74 & 3.0 & 1.64 \\
\hline Pronunciation bdg & .74 & 2.8 & 1.63 \\
\hline Adjective agreement & .72 & 2.1 & 1.29 \\
\hline Verb conjugation & .68 & 1.9 & 1.19 \\
\hline Sentence structure & .66 & 2.1 & 1.24 \\
\hline Spanish pronunciation & .64 & 2.3 & 1.24 \\
\hline Pronunciation r rr & .63 & 2.5 & 1.40 \\
\hline Fluency & .58 & 1.7 & 1.06 \\
\hline Comprehension & .40 & 3.4 & 1.76 \\
\hline
\end{tabular}

study directly with the objective linguistic measures detailed in Table 1 . Raters who are not linguists cannot be expected to make reasonable judgments about the complex aspects of speech measured in this study and it was quite likely that they did not have the vocabulary to understand or respond to such questions. The word 'diphthong' is encountered fairly frequently in language courses, but many raters asked that the word be defined when given a chance to ask questions before taking the test.

The relationship between subjective and objective measures may be understood better by comparing subjective measures of phonology and morphology with objectively derived rates of phonological and morphosyntactic accuracy. The intermediate speaker actually had a higher rate of morphosyntactic accuracy, and yet he was rated lower on items dealing with morphosyntactic accuracy than on phonological accuracy (see Table 2). This is fairly convincing evidence that the morphosyntactic errors were somewhat more salient than phonological ones, even though there was not sufficient difference in the ratings of morphosyntax and phonology to produce two language factors.

The factor analysis for the speaker of lower ability was quite interesting in that all questions dealing with vocabulary and syntax loaded to one factor and all pronunciation items loaded to a second factor (see Table 3). As in the case of the intermediate speaker, the speech of the beginner was rated lower on all items dealing with morphosyntax than those dealing with phonology. Looking at the objective measures of morphosyntax and phonology of the speech of the beginner, we find that his rate of morphosyntactic accuracy was $82 \%$ whereas his rate of phonological accuracy 
was $79 \%$ for consonants and only $70 \%$ for vowels. The case of the lower ability speaker even more convincingly demonstrates that pronunciation is less important than morphosyntax.

Table 3: 'Factor Analysis - Beginning Learner'

Factor 1-Morphology

\begin{tabular}{|c|c|c|c|}
\hline Item Label & Loadings & Means & $\underline{\text { Sigmas }}$ \\
\hline Vocabulary & .76 & 1.3 & .72 \\
\hline Confidence & .75 & 1.3 & .65 \\
\hline Adjective agreement & .73 & 1.7 & .88 \\
\hline Fluency & .72 & 1.3 & .70 \\
\hline Verb conjugation & .70 & 1.6 & .90 \\
\hline Sentence structure & .69 & 1.6 & 1.04 \\
\hline Appeal of accent & .52 & 1.5 & .96 \\
\hline \multicolumn{4}{|c|}{ Factor 2-Pronunciation } \\
\hline Item Label & Loadings & Means & Sigmas \\
\hline Pronunciation ptk & -.82 & 2.6 & 1.62 \\
\hline Pronunciation bdg & -.81 & 2.4 & 1.60 \\
\hline Vowels & -.75 & 2.3 & 1.35 \\
\hline Pronunciation $\mathrm{rrr}$ & -.63 & 2.1 & 1.26 \\
\hline Diphthongs & -.61 & 2.0 & 1.20 \\
\hline Spanish pronunciation & -.50 & 1.9 & 1.17 \\
\hline Comprehension & -.31 & 2.3 & 1.60 \\
\hline
\end{tabular}

Further evidence of the importance of morphosyntactic features to native listeners is the fact that of appeal of accent is correlated with the morphosyntactic factor extracted in the analysis of ratings of the speech of the beginning language learner; however, it is important to note that the correlation of appeal of accent with the underlying morphological factor (the 'loading') is only moderate and demonstrates that such a level of morphosyntactic inaccuracy is only somewhat "irritating."

The factor analysis of ratings of the beginner also provide interesting evidence regarding the relationship between comprehensibility and interlanguage. The factor labeled phonology consists of items evaluative of pronunciation (the negative signs may be ignored in comparing loadings as they are an artefact of the factor analysis and irrelevant to the issues at hand). The item dealing with comprehensibility of nonnative speech loads to the phonological factor, this despite the salience of morphosyntactic factors. The loading (or correlation) is weak and not well-related to this factor, but it is reasonable to assume that less accurate phonology (e.g., that of a first semester student) would lower comprehensibility of the learner's speech and that factor analysis of native speaker ratings of such speech would produce a phonological factor with which comprehensibility would be highly correlated.

\section{Pedagogical Implications}

The results of this study clarify and qualify previous findings reviewed by Ludwig and others. Morphological errors are apparently more salient than phonological ones in the speech of beginning second language learners. An error hierarchy based on the relative salience of morphological errors to native speakers is therefore empirically justified, but cannot be made any more specific since no particular type of error within either the morphological or phonological category is especially annoying or "irritating" to native speakers. At the intermediate level, no errors of any kind, either phonological or morphosyntactic, are salient. Native speaker response to intermediate interlanguage is global, which may be a response to the global language factor posited by Oller.

Communicatively-oriented textbook writers have deemphasized considerably the importance of discrete aspects of pronunciation and other areas of formal accuracy, concentrating instead on communicative effectiveness and fluency. In contrast, many high school and college textbooks are based on the audiolingual approach and emphasize correct pronunciation and native-like speed at the outset of a course. ${ }^{16}$ Many teachers have seen that even students trained to imitate accurately repeat typical pronunciation errors when attempting to communicate. The conclusion should be that teachers should not drill points of phonetic contrast since no error in particular is of importance to native speakers. Nevertheless, since phonology may be related to comprehensibility, teachers should encourage a global appreciation of the importance of good pronunciation at the beginning and throughout the formal instruction of the language learner. Since morphosyntax is demonstrably more important to native speakers, then perhaps that should be given more attention at the initial stages by providing more input of relevant, meaningful morphosyntactic data and corresponding structured feedback. Furthermore, the data suggest that if students venture out into the real linguistic world before attaining a rate of morphosyntactic accuracy of, say, at least $85 \%$, their interlanguage may be salient and irritating.

An error hierarchy which gives more impor- 
tance of morphosyntax than to phonology is valid at beginning levels, but the importance of such an error hierarchy based on language attitudes (and not on comprehensibility) must be qualified. The speakers in this study, measured on a scale from one to seven, were not given average ratings on any item of four or above, which would have indicated a neutral or positive evaluation of the speech. On every item, morphosyntactic or phonological, the language learners were given negative evaluations. This should underscore to the teacher that indeed it is important that the student gain a certain level of morphosyntactic and phonological accuracy. Even though native speakers did not correctly perceive that both speakers were actually more accurate in their morphosyntax than in pronunciation, the native speakers did correctly rate the beginner lower on both morphosyntax and phonology than the intermediate learner.

"Irritation" implies an affective response to a speech sample, yet affective ratings of interlanguage are indistinguishable from evaluative attitudes. Fishbein and Ajzen, among others, suggest that attitudes are largely evaluative. Nevertheless, in this study the more salient errors of a beginner appear to be "irritating.' Ludwig signals the importance of morphology, syntax and lexicon to comprehensibility and cites evidence to support the importance of those linguistic factors. Surprisingly, then, the present study indicates that comprehensibility is more related to phonological factors. Further study of native speaker comprehension and irritation using a large variety of interlanguage samples should help to determine at what level of linguistic ability both irritation and comprehension correlate highly with empirically derived linguistic factors. Such information will enable educators to develop instructional priorities based on error hierarchies.

\section{NOTES}

Jeannette Ludwig, "Native-Speaker Judgements of Second-Language Learners' Efforts at Communication: A Review," Modern Language Journal, 66 (1982), 27483.

"Kenneth Chastain, "Native Speaker Evaluation of Student Composition Errors," Modern Language Journal, 65 (1981), 288-94.

"Shaw N. Gynan, "The Attitudes of Native Spanish Speakers toward Taped Native and Nonnative Samples of Speech." Unpublished Ph. D Dissertation, The University of Texas at Austin, 1983.

${ }^{4}$ Robert P. Stockwell and J. Donald Bowen, The Sounds of English and Spanish (Chicago: U. Chicago Press, 1965), pp. 9-18.

"Vicki Galloway, "Perceptions of the Communicative Efforts of American Students in Spanish," Modern Language Journal, 64 (1980), 428-33.

"John Oller, "Evidence for a general language proficiency factor: an expectancy grammar," in Issues in Language Testing Research ed. John Oller, Rowley MA: Newbury House, 1983, pp. 3-10.

'Hossein Ferhady, "On the plausibility of the unitary language factor," in Issues in Language Testing ed. John Oller, Rowley MA: Newbury House, 1983, pp. 11-28.

'John Oller, footnote in Issues in Language Testing, ed. John Oller, Rowley MA: Newbury House, 1983, p. 27.

${ }^{9}$ Dorte Albrechtsen, B. Henriksen and C. Faerch, "Native Speaker Reactions to Learners' Spoken Interlanguage," Language Learning, 30 (1980), 365-96.

"Martin Fishbein and Icek Ajzen, Belief, Attitude, Intention, and Behavior: An Introduction to Theory and Research (Reading MA: Addison-Wesley, 1975), p. 6.

"Stephen Krashen, Second Language Acquisition and Second Language Learning (Elmsford NY: Pergamon, 1981), pp. 1-3.

${ }^{12}$ S. Pit Corder, "The Elicitation of Interlanguage," Errata (Lund, Sweden: Gleerup, 1973), pp. 36-47.

${ }^{1: W o l f g a n g ~ W o l c k, ~ " S p a n i s h ~ a n d ~ Q u e c h u a ~ i n ~ B i l i n g u a l ~}$ Peru," in R. Shuy and R. Fasold, eds., Language Attitudes: Current Trends and Prospects (Washington DC: Georgetown University, 1973), pp. 129-47.

${ }^{14}$ Donald J. Veldman, The Prime System: Computer Programs for Statistical Analysis (Austin TX: Research and Development Center for Teacher Education, The University of Texas at Austin, 1978), pp. 73-79.

${ }^{15}$ Howard Maclay and Charles E. Osgood, "Hesitation Phenomena in Spontaneous English Speech," Word, 15 (1959), 19-54.

${ }^{16}$ Karl Diller, The Language Teaching Controversy (Rowley MA: Newbury House, 1978), pp. 5-7. 